\title{
Inhibiting Aspergillus flavus Growth and Aflatoxin Decrement in Aquatic Feed with Satureja hortensis Essential Oil
}

\section{LALEH YAZDANPANAH GoHARRIZI ${ }^{1 *}$, SHIMA TASHAROFI ${ }^{2}$}

\section{${ }^{1}$ Department of Fisheries Science Researches; ${ }^{2}$ Department of Animal Science Researches, Agriculture and Natural Resources Education and Research Centre, Kerman, Iran.}

\begin{abstract}
Aspergillus flavus from inner part of pistatue was placed on the surface of PDA media culture to produce the spores. Then, different doses (400, 500 and $600 \mathrm{ppm}$ ) of savory (Satureja hortensis) essential oil (specifying its component by GC/MS analysis) were added to media to determine its effects as fungal inhibitor. Also, fish feed samples (300 g each) combined with above-mentioned doses of savory essential oil were inoculated with $2 \mathrm{ml}$ spore suspension to evaluate fungal inhibit of savory oil at feed by HPLC method. The extent of the inhibition of fungal growth and aflatoxin $(\mathrm{AF})$ production was dependent on the concentration of essential oil applied. The results indicate that Carvacrol (41.239\%) and thymol (20.718\%) are the most ingredients of savory oil and use of 500 and $600 \mathrm{ppm}$ savory essential oil in aquatic feeds decrease $\mathrm{AF}$ contamination produced by Aspergillus flavus and it could be an appropriate alternative to chemical anti-fungi compounds.
\end{abstract}

Keywords | Aflatoxin, Carvacrol, Fish feed, Savory, Thymol

Editor | Muhammad Abubakar, National Veterinary Laboratories, Islamabad, Pakistan.

Received | November 06, 2016; Accepted | December 06, 2016; Published | December 13, 2016

*Correspondence | Laleh Yazdanpanah Goharrizi, Department of Fisheries Science Researches; Agriculture and Natural Resources Education and Research Centre, Kerman, Iran; Email: 1_yazdanpanah@yahoo.com

Citation | Yazdanpanah Goharrizi L, Tasharofi S (2017). Inhibiting Aspergillus flavus growth and aflatoxin decrement in aquatic feed with Satureja hortensis essential oil. Res. J. Vet. Pract. 4(4): 71-75.

DOI | http://dx.doi.org/10.14737/journal.rjvp/2016/4.4.71.75

ISSN | 2308-2798

Copyright $(\subseteq 2017$ Goharrizi and Tasharofi. This is an open access article distributed under the Creative Commons Attribution License, which permits unrestricted use, distribution, and reproduction in any medium, provided the original work is properly cited.

\section{INTRODUCTION}

A flatoxins (AFs) are important fungal toxic compounds which are produced by an expanding list of closely related fungi (Eaton and Groopman, 1994). $\mathrm{AFB}_{1}$ is the most important toxic compound among all known AFs' that causes serious risk to human and animal health (Diaz et al., 2009; Sepahdari et al., 2010). Despite the interesting data have now been exist about $\mathrm{AFB}_{1}$ in animals, the presence and impact of $\mathrm{AFB}_{1}$ in farmed aquatic species are still underestimated. Very little has been documented on the toxicity of $\mathrm{AFB}_{1}$ for cultured aquatic invertebrates fed by artificially contaminated diets (Alinezhad et al., 2011). The history of AFs in fish returns to 1960 when a prevalence of liver tumors was reported in rainbow trout hatcheries in USA due to fed with AF contaminated cottonseed meal as a raw ingredient in trout meal (Ashley and
Halver, 1963). AF contamination of feed and feed ingredients used in aquaculture has been reported for a wide range of substrates including rice, maize, peanuts, cottonseed, fish meal and dried fish (Ashley and Halver, 1963; Ashley, 1970). AFs demonstrate a fundamental impact on the fish farming production, causing anemia, hemorrhage, liver damage, weight loss, increased susceptibility to secondary infectious diseases, increased mortality and a gradual decline of reared fish stock quality, thus representing a significant problem in aquaculture systems (Santacroce et al., 2008). Also, this toxin affects some hydrothermal fishes such as channel catfish and tilapia due to more use of plant compounds in comparison to animal compounds (Gowda et al., 2004) that plant compounds are more sensitive to AFs. Improper methods of feed processing and storage are among the most important factors favouring the growth of AF-producing moulds and they are major elements that 
can be controlled by the fish producer (Fraga et al., 2007).

During the last decade, development of antibiotic resistance as well as unpleasant side effects of some antibiotic drugs has terminated to the investigation for new antimicrobial agents. Also, a lot of people are interested in usage of organic productions (Rasooli et al., 2008). Therefore, many researchers have experimented the antimicrobial activity and other biological effects of different plants and their essential oils.

Satureja hortensis (Savory) belongs to the Lamiaceae family and is a medical herb which grows in more than $30 \mathrm{hec}-$ tares of Iran. It has been traditionally used as diuretic, carminative, anti-diarrheal and intensive disinfectant. Some biological effects of savory such as antiviral, anti-inflammatory, antimicrobial and antifungal have been confirmed (Razzaghi-Abyaneh et al., 2008). About 2-5 ml essential oil is obtained from every $100 \mathrm{~g}$ savory which the aim of the recent study was therefore to evaluate the antifungal effect of essential oil of savory and its impression on toxin prevention in aquatic diet.

\section{MATERIAL AND METHODS}

The protocol of the experiment was reviewed and approved by the Animal Science Research Department of Agriculture and Natural Resource Education and Research Center of Kerman, Iran.

\section{Essential Oil and GC/MS Analysis}

The essential oils from aerial parts of savory were prepared from Barij Essence Pharmaceutical Company (Kashan, Iran) for this experimental trial. The samples were stored at $4^{\circ} \mathrm{C}$ until used. The oil analysis was done using GC and GC/MS. The GC device was Shinadzu-9A system equipped with F.I.D detector and Chromatepac data-processor, capillary column of DB-5 $(30 \mathrm{~m} \times 0.25 \mathrm{~mm}$, film thickness $0.25 \mu \mathrm{m})$. The oven temperature program was raised up to $100-220^{\circ} \mathrm{C}$ at a rate of $2^{\circ} \mathrm{C} / \mathrm{min}$. The injector temperature was $230^{\circ} \mathrm{C}$. Helium was used as the carrier gas at a flow rate $22.7 \mathrm{~cm} / \mathrm{s}$ and ionization energy in mass spectrophotometer was 70 electron volts. GC/ MS analysis was done on a Varin-3400 GC system connected to Saturn 2 mass spectrometer with the same-above-mentioned capillary column, ion trap detector, carrier gas helium with flow rate $50 \mathrm{~cm} / \mathrm{s}$, ionization energy in mass spectrometer 70 electron volts, with temperature program $60-240^{\circ} \mathrm{C}$ at a rate of $3^{\circ} \mathrm{C} / \mathrm{min}$ and injector temperatures $250^{\circ} \mathrm{C}$. The compounds of the oil were identified by comparison of their retention indices (RI), mass spectra fragmentation with those on the stored Wiley 7 n. 1 mass computer library, and NIST (National Institute of Standards and Technology) (Mahboubi and Kazempour, 2011).
Microbial Strains and Purification of Pathogen Pathogen fungi of Aspergillus flavus PTCC5006IR6 from inner part of Rafsanjan pistatue was obtained from Persian Type Culture Collection (Tehran, Iran) as a lyophilized fungus with bigh toxin production. At first, fungus was placed on the surface of PDA (potato dextrose agar) media culture and petri dishes were incubated for $7-10$ days in $28 \pm 2^{\circ} \mathrm{C}$ to produce the spores. Isolates were purified by single spore methods. The media culture was used after the fourth stage of processing and preparation (passage) of pure cultures.

\section{Sample Preparation}

At first, different doses of savory essential oil (400, 500 and $600 \mathrm{ppm}$ ) were added to media and flasks were inoculated with discs of $1 \mathrm{~cm}$ diameter of the toxigenic Aspergillus flavus. Prepared petri dishes were used to determine its effects as fungal inhibitor. Secondly, fish feed samples (300 g each) were weighted in containers. Prepared containers were autoclaved in $121^{\circ} \mathrm{C}$ for 15 minutes to be sterile. Then, different doses of savory essential oil (400, 500 and $600 \mathrm{ppm}$ ) in $3 \mathrm{ml}$ of distilled water (to supply moisture) were prepared and added to feed samples. Three replicates were performed for each concentration and control was carried out with $3 \mathrm{ml}$ distilled water. The samples were inoculated with $2 \mathrm{ml}$ spore suspension in sterile conditions under microbial hood. Dishes were incubated at $28 \pm 2^{\circ} \mathrm{C}$ and shook every 24 hours to assimilate oxygen, fungal infection and savory essential oil in the whole of media culture. Light, temperature and oxygen conditions were similar for all samples.

\section{DeTERMination OF HPLC}

The first, second and third samplings were done After 20, 40 and 60 days of the inoculation, respectively. Analysis of compounds was performed on Aflatoxins by High-Performance Liquid Chromatography (HPLC) model (model PerkinElmer series 200UV/VIS) with a C18 column with an internal diameter of $300 \mathrm{~mm} \times 3.9 \mathrm{~mm}, 4$ micron. The HPLC was equipped with an UV detector and fluorescence with $365 \mathrm{~nm}$ excitation and 430 emission wavelengths. The mobile phase consists of methanol:acetic acid:water $(20: 20: 60 \mathrm{v} / \mathrm{v} / \mathrm{v})$. The total run time for the separation was approximately $25 \mathrm{~min}$ at a flow rate of $1 \mathrm{ml} / \mathrm{min}$ (Christian, 1990; Abd-El-Aziz et al., 2015).

\section{Statistical Analysis}

All of the data were analyzed using SPSS 10.0 statistical software and significant differences between mean values were determined with Duncan's multiple range test $(P<$ 0.05), followed by one-way ANOVA.

\section{RESULTS}

INGREDIENTS OF Savory Essential OIL

Table 1 shows the ingredients of savory oil. Carvacrol 


\section{OPEN 0 ACCESS}

(41.239\%), thymol (20.718\%), $\gamma$-terpinene (16.498\%) and P-cymene (10.082\%) were the main components of savory oil. $\alpha$-terpinene $(4.498 \%), \beta$-pinene $(0.588 \%), \alpha$-pinene $(1.480 \%)$ and myrcene $(1.788 \%)$ were the other minor components of oil.

Table 1: Ingredients of savory oil

\begin{tabular}{|llll|}
\hline Name of Compound & $\%$ & Name of Compound & \% \\
\hline Alpha - thujene & 1.008 & Limonene & 0.755 \\
\hline Alpha- pinene & 1.480 & Gamma-terpinene & 16.498 \\
\hline Beta- pinene & 0.588 & Thymol & 20.718 \\
\hline Myrcene & 1.788 & Carvacrol & 41.239 \\
\hline Alpha- phellandrene & 0.287 & e- caryophyllene & 0.538 \\
\hline Alpha-terpinene & 4.498 & p- cymene & 10.082 \\
\hline Beta-bisabolene & 0.527 & & \\
\hline
\end{tabular}

Detection of AFB ${ }_{1}, \mathrm{G}_{1}$ and Total $\mathrm{B}_{1}, \mathrm{~B}_{2}, \mathrm{G}_{1}, \mathrm{G}_{2}$ Produced by Aspergillus flavus in Confronting WITH Savory OIL

Data in Table 2 shows the amount of AFs faced to different doses of savory oil in different days of sampling. Obviously, since day 40 onwards, 500 and 600 ppm savory oil decreased all kinds of $\mathrm{AFB}_{1}$ and total $\mathrm{B}_{1}, \mathrm{~B}_{2}, \mathrm{G}_{1}, \mathrm{G}_{2}$. Results of $\mathrm{AFG}_{1}$ indicate that 500 and 600 ppm savory essential oil in all days declined this kind of fungal toxin.

Detection of AFB, $\mathrm{G}_{1}$ And Total $\mathrm{B}_{1}, \mathrm{~B}_{2}, \mathrm{G}_{1}, \mathrm{G}_{2}$ Produced by Aspergillus flavus in Confronting with Savory Oil at Aluatic Feed Samples

Effect of different doses of savory essential oil on $\mathrm{AFB}_{1}$ and $G_{1}$ inhibit at aquatic feed samples during different days are shown in Table 3. Amount of $\mathrm{AFB}_{1}$ reduced linearly during time in all feed samples including control but noticeably, all doses of savory essential oils (400, 500 and $600 \mathrm{ppm}$ ) could completely inhibit fungi growth in feed samples at day 60 of experimental period. On the other hand, although savory essential oil decreased amount of $\mathrm{AFG}_{1}$ at aquatic feed samples at day 20 but its effect did not continue until days 40 and 60 which are apparent in Table 3.

\section{DISCUSSION}

Data show that 500 and 600 ppm savory essential oil appeared effective on the growth inhibit of fungi compared to control. There is an upstanding relationship between the inhibitory effect of the essential oils and their doses (AbdEl-Aziz et al., 2015, Al-Gahtani et al., 2013; Rasooli et al., 2008). The results indicate that the test toxigenic fungus is sensitive to the savory essential oil and particularly sensitive to doses upper than $500 \mathrm{ppm}$. This result is confirmed by some other researchers (Atanda et al., 2007; Eweis et al., 2012).

Chemical composition of savory oil exhibited the presence of thymol, $\gamma$-terpinene, p-cymene and carvacrol as the main component. In the present study, carvacrol was the main component of savory oil. It is a monoterpenoid phenol. It has a pungent and warm odour characteristic. Thymol was identified as the second most common compound in savory oil and it is part of a naturally occurring class of compounds known as biocides, with strong antimicrobial attributes when used alone or with other biocides such as carvacrol.

Table 2: Effect of different doses of savory oil on amount of AFs

\begin{tabular}{|c|c|c|c|c|c|c|c|c|c|}
\hline \multirow{2}{*}{$\begin{array}{l}\text { Treat- } \\
\text { ments }\end{array}$} & \multicolumn{3}{|l|}{$\mathrm{AFB}_{1}$} & \multicolumn{3}{|l|}{$\mathrm{AFG}_{1}$} & \multicolumn{3}{|c|}{ Total AFB ${ }_{1} B_{2} G_{1} G_{2}$} \\
\hline & Day 20 & Day 40 & Day 60 & Day 20 & Day 40 & Day 60 & Day 20 & Day 40 & Day 60 \\
\hline Control & $0.53 \pm 0.012$ & $0.57^{\mathrm{a}} \pm 0.028$ & $1.13^{\mathrm{a}} \pm 0.035$ & $1.99^{\mathrm{a}} \pm 0.040$ & $1.21^{\mathrm{a}} \pm 0.041$ & $1.49^{a} \pm 0.038$ & $1.89 \pm 0.201$ & $1.78^{\mathrm{a}} \pm 0.084$ & $2.62^{a} \pm 0.328$ \\
\hline 400 ppm & $0.53 \pm 0.014$ & $0.58^{\mathrm{a}} \pm 0.017$ & $0^{\mathrm{b}} \pm 0$ & $2.10^{a} \pm 0.051$ & $1.11^{\mathrm{a}} \pm 0.038$ & $0.48^{\mathrm{ab}} \pm 0.020$ & $1.93 \pm 0.196$ & $0.82^{\mathrm{b}} \pm 0$. & $0.82^{b} \pm 0.182$ \\
\hline $500 \mathrm{ppm}$ & $0.56 \pm 0.022$ & $0.22^{\mathrm{b}} \pm 0.021$ & $0^{\mathrm{b}} \pm 0$ & $1.19^{\mathrm{bc}} \pm 0.032$ & $0.64^{\mathrm{b}} \pm 0.021$ & $0.24^{\mathrm{b}} \pm 0.015$ & $1.75 \pm 0.141$ & $0.86^{b} \pm 0.195$ & $0.52^{b} \pm 0.020$ \\
\hline $600 \mathrm{ppm}$ & $0.56 \pm 0.018$ & $0.15^{\mathrm{b}} \pm 0.019$ & $0^{\mathrm{b}} \pm 0$ & $0.87^{\complement} \pm 0.021$ & $0.44^{b} \pm 0.017$ & $0.15^{\mathrm{b}} \pm 0.012$ & $1.46 \pm 0.093$ & $0.84^{b} \pm 0.068$ & $0.15^{c} \pm 0.064$ \\
\hline$P$ value & 0.226 & 0.000 & 0.000 & 0.025 & 0.030 & 0.009 & 0.527 & 0.016 & 0.021 \\
\hline
\end{tabular}

$\mathrm{a}, \mathrm{b}, \mathrm{c}$, Means within a column with different subscripts $\operatorname{differ}(\mathrm{P}<0.05)$

Table 3: Effect of different doses of savory oil on amount of AFs at aquatic feed samples

\begin{tabular}{|c|c|c|c|c|c|c|c|c|c|}
\hline \multirow{2}{*}{$\begin{array}{l}\text { Treat- } \\
\text { ments }\end{array}$} & \multicolumn{3}{|l|}{$\mathrm{AFB}_{1}$} & \multicolumn{3}{|l|}{$\mathrm{AFG}_{1}$} & \multicolumn{3}{|c|}{ Total $A F B_{1} B_{2} G_{1} G_{2}$} \\
\hline & Day 20 & Day 40 & Day 60 & Day 20 & Day 40 & Day 60 & Day 20 & Day 40 & Day 60 \\
\hline Control & $0.58 \pm 0.051$ & $0.34^{a} \pm 0.063$ & $0.24^{a} \pm 0.059$ & $1.20^{\mathrm{a}} \pm 0.037$ & $0.62 \pm 0.029$ & $0.72 \pm 0.021$ & $1.58 \pm 0.121$ & $1.84^{a} \pm 0.115$ & $1.76^{\mathrm{a}} \pm 0.103$ \\
\hline 400 ppm & $0.53 \pm 0.038$ & $0.40^{\mathrm{a}} \pm 0.051$ & $0^{\mathrm{b}} \pm 0$ & $1.25^{\mathrm{a}} \pm 0.042$ & $0.45 \pm 0.033$ & $0.50 \pm 0.037$ & $1.43 \pm 0.320$ & $0.93^{b} \pm 0.103$ & $0.87^{b} \pm 0.992$ \\
\hline $500 \mathrm{ppm}$ & $0.57 \pm 0.049$ & $0.22^{\mathrm{b}} \pm 0.071$ & $0^{\mathrm{b}} \pm 0$ & $1.20^{a} \pm 0.039$ & $0.59 \pm 0.027$ & $0.75 \pm 0.022$ & $1.69 \pm 0.211$ & $0.81^{b} \pm 0.093$ & $0.93^{b} \pm 0.121$ \\
\hline 600 ppm & $0.58 \pm 0.057$ & $0.15^{b} \pm 0.068$ & $0^{\mathrm{b}} \pm 0$ & $0.90^{b} \pm 0.051$ & $0.68 \pm 0.035$ & $0.71 \pm 0.030$ & $1.80 \pm 0.187$ & $0.98^{b} \pm 0.098$ & $0.61^{\mathrm{b}} \pm 0.143$ \\
\hline$P$ value & 0.826 & 0.014 & 0.005 & 0.024 & 0.308 & 0.481 & 0.299 & 0.037 & 0.041 \\
\hline
\end{tabular}

a,b, Means within a column with different subscripts differ $(\mathrm{P}<0.05)$ 
$\gamma$-terpinene was the third component of this oil that is natural and has been isolated from a variety of plant sources. The fourth most abundant compound was $\mathrm{P}$-cymene which is a naturally aromatic compound classified as monoterpene hydrocarbon consisting of a benzene ring substituted with a methyl and isopropyl groups (Kedia et al., 2014; Mahboubi and Kazempour, 2011).

Antimicrobial activities of this essential oil is apparently attributable to high phenolic compounds such as thymol and carvacrol (Mahboubi and Ghazian bidgoli, 2010; Gowda et al., 2004; Boyraz and Ozcan, 2006; Gulluce et al., 2003), or $\mathrm{p}$-cymene. The antimicrobial effect of thymol and carvacrol is due to damage in membrane integrity with change in $\mathrm{pH}$ hemostasis also equilibrium of inorganic ions, $\mathrm{p}-\mathrm{cy}-$ mene does not have antimicrobial activity but it increases the antimicrobial activity of thymol or carvacrol (Delgado et al., 2004; Ultee et al., 2002). P-cymene is hydrophobic compound with ability to dissolve cytoplasmic membrane of bacterial cells (Mahboubi and Kazempour, 2011). Also, based on Dikbas et al. (2008) report, AFs inhibit effects of carvacrol is more than thymol but all major and/or minor components of savory essential oil play an important role on its antimicrobial activities. It is found that the whole essential oils have a greater antibacterial activity than the mixed major component (Mourey and Canillac, 2002) so the minor components of essential oil play a critical role for activity of oil.

Regional differences in AFs contamination of herbal foods may be attributable to climatic conditions and to agricultural practices. Humidity (Nawar, 2008), pre-harvest conditions of temperature and humidity in the field and improper post-harvest handling and storage (Nakai et al., 2008; Khodavaisy et al., 2012) play a fundamental role in the development and spread of fungal contaminations.

It has been reported that savory essential oil decreases mycelium weight of Aspergillus flavus (Dikbas et al., 2008), inhibits growth of $\mathrm{AFB}_{1}$ and $\mathrm{G}_{1}$ produced by Aspergillus parasiticus (Razzaghi et al., 2008), prevents toxigenic fungi in plants and foods (Maskouki and Mortazavi, 2004) and has intensive antimicrobial activity (Mahboubi and Kazempour, 2011).

Results from current experiment indicates that use of more than 500 ppm savory essential oil in aquatic feeds decrease AFs contamination produced by Aspergillus flavus and it might be an appropriate alternative to chemical anti-fungi compounds.

\section{AUTHORS' CONTRIBUTION}

Both authors contributed equally in this article.

\section{REFERENCES}

-Abd-El-Aziz ARM, Mahmoud MA, Al-Othman MR, Al-Gahtani MF (2015). Use of essential oils to control aflatoxin contaminated stored cashew and detection of aflatoxin biosynthesis gene. Sci. World J. https://doi. org/10.1155/2015/958192

-Al-Gahtani MF, Al-Othman RM, Mahmoud MA, Abd-E1Aziz ARM (2013). Anti-aflatoxigenic effect of essential oils on Aspergillus spp. isolated from pistachio in Saudi Arabia. African J. Microbiol. Res. 7(25): 3151-3159. https://doi. org/10.5897/AJMR2013.5670

-Alinezhad S, Tolouee M, Kamalzadeh A, Motalebi AA, Nazeri M, Yasemi M, Shams-Ghahfarokhi M, Tolouei R, Razzaghi-Abyaneh M (2011). Mycobiota and aflatoxin B1 contamination of rainbow trout (Oncorbinchus mykiss) feed with emphasis to Aspergillus section Flavi. Iran. J. Fish. 10(3): 363-374.

-Ashley LM (1970). Pathology of fish fed aflatoxins and other antimetabolites. A symposium on diseases of fishes and shellfishes. American Fisheries Society, Washington, D.C. Pp. 366-379. https://doi.org/10.1577/15488659(1963)92[365:MMORTH]2.0.CO;2

-Ashley LM, Halver JE (1963). Multiple metastasis of rainbow trout hepatoma. Trans. Am. Fish. Soc. 92: 365-371.

-Atanda OO, Akpan I, Oluwafemi F (2007). The potential of some spice essential oils in the control of $A$. parasiticus $\mathrm{CFR}$ 223 and aflatoxin production. Food Contr. 18(5): 601-607. https://doi.org/10.1016/j.foodcont.2006.02.007

-Boyraz N, Ozcan M (2006). Inhibition of phytopathogenic fungi by essential oil, hydrosol, ground material and extract of summer savory (Satureja hortensis L.) growing wild in Turkey. Int. J. Food Microbiol. 107: 238-242. https://doi. org/10.1016/j.ijfoodmicro.2005.10.002

-Christian (1990). HPLC Tips and Tricks, Iden Press, Oxford, UK.

-Delgado B, Fernandez PS, Palop A, Periago PM (2004). Effect of thymol and cymene on Bacillus cereus vegetative cells evaluated through the use of frequency distributions. Food Microbiol. 21: 327-334. https://doi.org/10.1016/S07400020(03)00075-3

-Diaz GJ, Lozano MC, Acuna A (2009). Prevalence of Aspergillus species on selected Colombian animal feedstuffs and ability of Aspergillus section Flavi to produce aflatoxins. World Mycotoxin J. 2: 31-34. https://doi.org/10.3920/ WMJ2008.1041

-Dikbas N, Kotan R, Dadasoglu F, Sahin F (2008). Control of Aspergillus flavus with essential oil and methanol extract of Satureja hortensis. Int. J. Food Microbiol. 124: 179-182. https://doi.org/10.1016/j.ijfoodmicro.2008.03.034

-Eaton DL, Groopman JD (1994). Aflatoxins: Human Health. Veterinary and Agricultural significance. Academic Press, New York, USA. Pp. 327-340.

•Eweis M, Imhemmed AA, Gad AS (2012). Influence of Thymus serpyllum essential oil on Aspergillus parasiticus morphology and aflatoxins production. Res. J. Pharma. Biol. Chem. Sci. 3(2): 322-332.

- Fraga ME, Curvello F, Gatti MJ, Cavaglieri LR, Dalcero AM, Rocha-Rosa CA (2007). Potential aflatoxin and ochratoxin: A production by Aspergillus species in poultry feed processing. Vet. Res. Commun. 31: 343-353. https://doi.org/10.1007/ s11259-006-3434-x

- Gowda NKS, Melati V, Saganthi RU (2004). Effect of some 
chemical and herbal compounds on growth of Aspergillus parasiticus and aflatoxin production. Anim. Feed Sci. Technol. 116: 281-291. https://doi.org/10.1016/j. anifeedsci.2004.02.008

- Gulluce M, Sokmen M, Daferera D, Agar G, Ozkan H, Kartal N, Polissiou M, Sokmen A, Sahin F (2003). In vitro antibacterial, antifungal and antioxidant activities of the essential oil and methanol extracts of herbal parts and callus cultures of Satureja hortensis L. J. Agric. Food Chem. 51(14): 3958-3965. https://doi.org/10.1021/jf0340308

-Kedia A, Prakash B, Mishra PK, Dubey NK (2014). Antifungal and antiaflatoxigenic properties of Cuminum cyminum (L.) seed essential oil and its efficacy as a preservative in stored commodities. Int. J. Food Microbiol. 168: 1-7. https://doi. org/10.1016/j.ijfoodmicro.2013.10.008

-Khodavaisy S, Maleki A, Hossainzade B (2012). Occurrence of fungal contamination in pistachio and peanut samples from retail shops in Sanandaj province. African J. Microbiol. Res. 6: 6781-6784. https://doi.org/10.5897/AJMR12.722

-Mahboubi M, Ghazian Bidgoli F (2010). Antistaphylococcal activity of Zataria multiflora essential oil and its synergy with vancomycin. Phytomedicine. 17: 548-550. https://doi. org/10.1016/j.phymed.2009.11.004

- Mahboubi M, Kazempour N (2011). Chemical composition and antimicrobial activity of Satureja hortensis and Trachyspermum copticum essential oil. Iran. J. Microbiol. 3(4): 194-200.

-Maskuki A, Mortazavi SA (2004). Antifungal activity of essential oils of Thymus vulgaris and Trachyspermum ammi against Aspergilus. Sci. Technol. Agric. Nat. Resour. 8(2): 207-215.

-Mourey A, Canillac N (2002). Anti-Listeria monocytogenes activity of essential oils components of conifers. Food Contr. 13: 289-292. https://doi.org/10.1016/S09567135(02)00026-9
- Nakai VK, Rocha LDO, Goncalez E, Fonseca H, Ortega EMM, Correa B (2008). Distribution of fungi and aflatoxins in a stored peanut variety. Food Chem. 106(1): 285-290. https:// doi.org/10.1016/j.foodchem.2007.05.087

- Nawar LS (2008). Prevention and control of fungi contaminated stored pistachio nuts imported to Saudi Arabia. Saudi J. Biol. Sci. 15: 105-112.

-Rasooli I, Fakoor MH, Yadegarinia D, Gachkar L, Allameh A, Rezaei MB (2008). Antimycotoxigenic characteristics of Rosmarinus officinalis and Trachyspermum copticum L. essential oils. Int. J. Food Microbiol. 122(1-2): 135-139. https://doi.org/10.1016/j.ijfoodmicro.2007.11.048

-Razzaghi-Abyaneh M, Ghahfarokhi S, Yoshinari M, Rezaee T, Jaimand MB, Nagasawa K, Sakuda S (2008). Inhibitory effects of satureja hortensis L. essential oil on growth and aflatoxin production by Aspergillus parasiticus. Int. J. Food Microbiol. 123: 228-233. https://doi.org/10.1016/j. ijfoodmicro.2008.02.003

-Santacroce MP, Conversano MC, Casalino E, Lai O, Zizzadoro C, Centoducati G, Crescenzo G (2008). Aflatoxins in aquatic species: metabolism, toxicity and perspectives. Rev. Fish Biol. Fish. 18: 99-130. https://doi.org/10.1007/ s11160-007-9064-8

-Sepahdari A, Ebrahimzadeh Mosavi HA, Sharifpour I, Khosravi A, Motallebi AA, Mohseni MS, Kakoolaki S, Pourali R, Hallajian A (2010). Effects of different dietary levels of $\mathrm{AFB}_{1}$ on survival rate and growth factors of Beluga (Huso buso). Iran. J. Fish. Sci. 9(1): 141-150.

-Ultee A, Bennik MHJ, Moezelar R (2002). The phenolic hydroxyl group of carvacrol is essential for action against the foodborne pathogen Bacillus cereus. Appl. Environ. Microbiol. 68: 1561-1568. https://doi.org/10.1128/AEM.68.4.15611568.2002 